\title{
Efeito da adubação nitrogenada e irrigação sobre a composição químico- bromatológica das lâminas foliares e da planta inteira de capim-elefante sob pastejo ${ }^{1}$
}

\author{
Claudio Mistura ${ }^{2}$, Dilermando Miranda da Fonseca ${ }^{3}$, Luciano de Melo Moreira ${ }^{4}$, Jailson Lara \\ Fagundes $^{5}$, Rodrigo Vieira Morais ${ }^{6}$, Augusto César de Queiroz ${ }^{7}$, José Ivo Ribeiro Júnior ${ }^{8}$ \\ ${ }_{1}$ Parte da tese do primeiro autor, pesquisa financiada pela FAPEMIG. \\ 2 Departamento de Tecnologia e Ciências Sociais (DTCS) da Universidade do Estado da Bahia (UNEB), Campus III - Juazeiro - BA. Av. Edgard \\ Chastinet, S/N, Bairro São Geraldo, CEP:48905-680 - Juazeiro - BA. Fone/Fax: (074) 6311-7363. \\ ${ }^{3}$ Departamento de Zootecnia - UFV, Viçosa - MG. \\ ${ }^{4}$ Faculdade de Estudos Administrativos de Minas Gerais. \\ 5 Pólo Regional da Alta Paulista - APTA/SSA/SP. \\ ${ }^{6}$ Escola Agrotécnica Federal de Muzambinho. \\ 7 Departamento de Zootecnia - UFV, Viçosa - MG. \\ ${ }^{8}$ Departamento de Informática - UFV, Viçosa - MG.
}

RESUMO - Esta pesquisa foi desenvolvida com o objetivo de avaliar o efeito da adubação nitrogenada (100, 200, $300,400 \mathrm{~kg} / \mathrm{ha} /$ ano de N) e da irrigação (área irrigada - AI e não-irrigada - ANI) sobre a composição quimico-bromatológica da planta inteira (PI) (colmo+folha) e das lâminas foliares dos perfilhos basais não-decapitados (LF-PBNd) e decapitados (LF-PBd) do capim-elefante cv. Napier. Adotou-se delineamento experimental em blocos casualizados com três repetições, em que a unidade experimental consistiu de parcelas (piquetes de $300 \mathrm{~m}^{2}$ ), nas quais foram aplicados os tratamentos. Os teores de PB apresentaram valores proporcionais às doses de nitrogênio, observando-se os maiores valores, no período das águas, nas LF-PBNd e LF-PBd. Os resíduos das doses $\mathrm{N}$ aplicados no período chuvoso tanto na AI como ANI elevaram os teores de PB nas lâminas foliares das duas categorias de perfilhos, mas não sobre os teores de FDN e FDA. A irrigação proporcionou teores de FDN e FDA mais elevados nas LF-PBNd e LF-PBd e menores na planta inteira, porém, não se observou efeito sobre os teores de PB.

Palavras-chave: adubação, gramínea tropical, Pennisetum purpureum

\section{Effect of nitrogen fertilization and irrigation on the chemical composition of the leaf blade and whole plant of elephantgrass under grazing}

\begin{abstract}
This research was carried out to evaluate the chemical composition of elephantgrass cv. Napier in the whole plant (WP) (stem+leaf) and in the leaf blade of non-decapitated basal tillers (SF-NDBT) and leaf blade of decapitated basal tillers (SF-DBT), fertilized with different $\mathrm{N}$ doses $(100,200,300$, and $400 \mathrm{~kg} / \mathrm{ha} / \mathrm{year}$ of $\mathrm{N}$ ) in an irrigated area (IA) and in a non-irrigated area (NIA). Treatments were analyzed in a randomized block design with three replicates. The CP concentrations were proportional to the $\mathrm{N}$ doses with greater $\mathrm{CP}$ concentration in the rainy season in fractions SF-NDBT and SF-DBT. Fertilizer residues of $\mathrm{N}$ doses applied in the rainy season, both in IA and NIA, increased CP concentration in the leaf blade of the two tiller categories, but did not affect NDF and ADF concentration. Irrigation increased concentration of NDF and ADF in SF-NDBT and SF-DBT and reduced it in the WP, with no effect on CP concentration.
\end{abstract}

Key Words: fertilization, Pennisetum purpureum, tropical grass

\section{Introdução}

Regiões com condições edafoclimáticas favoráveis ao cultivo de espécies forrageiras de alto potencial produtivo e com extensões territoriais iguais às do Brasil, têm despertado interesse por implantação de sistemas de produção à base de pastos como principal recurso forrageiro, pois é uma alternativa de alimentação mais econômica na qual se obtém carne de boa qualidade. Nestas condições, a produção bovina brasileira torna-se mais competitiva em novos mercados exportadores, por apresentar menor custo de produção e qualidade que os outros sistemas de produção.

Por outro lado, na maioria das regiões tropicais do Brasil, existem duas estações definidas, uma desfavorável ao crescimento das plantas forrageiras (período seco) e outra favorável (período das águas). Esta estacionalidade 
das forrageiras durante o período seco (abril a setembro) tem-se tornado uma das principais causas dos baixos desempenhos zootécnicos dos rebanhos brasileiros criados em pasto.

A baixa produção e, em parte, o comprometimento de sua qualidade no período seco, podem, segundo Ferreira (1998), ser atribuídos ao déficit no balanço hídrico, ao fotoperíodo mais curto e às baixas temperaturas noturnas no inverno. A falta de água impõe limitações à taxa de expansão de folhas, ao número de folhas por perfilho e ao número de perfilhos (Corsi et al., 1998). Contudo, o capimelefante tem se mostrado uma forrageira de alta competitividade em relação a outras espécies recomendadas para pastejo, sob condições de irrigação e adubação, por possuir maior eficiência no acúmulo de forragem por área, o que pode ser interessante em sistemas intensivos de exploração.

Neste contexto, a eficiência de utilização destas plantas forrageiras pelos animais depende de vários fatores como a qualidade e quantidade de forragem disponível na pastagem e o potencial do animal. Assim, quando a disponibilidade de forragem e o potencial do animal não são limitantes, a qualidade da pastagem é definida pela produção por animal e está diretamente relacionada ao consumo voluntário e à disponibilidade dos nutrientes (Reis \& Rodrigues, 1993). Portanto, forragens de alta qualidade devem fornecer energia, proteína, minerais e vitaminas para atender às exigências dos animais em pastejo. A composição química pode ser utilizada como característica de qualidade das espécies forrageiras, porém depende de aspectos de natureza genética e ambiental; além disso, não deve ser utilizada como o único determinante da qualidade de um pasto. A composição química e a digestibilidade variam, entre outros fatores, com a espécie, o estádio de maturidade, os fatores climáticos e o nível de inserção da folha no perfilho (Gerdes et al., 2000; Paciullo et al., 2001; Queiroz et al., 2000; Wilson et al., 1991).

Os componentes químicos das plantas também variam conforme os diferentes tecidos e órgãos, em razão de especificidade da organização física das células vegetais. Entretanto, de modo geral, os principais constituintes químicos das plantas forrageiras podem ser divididos em duas grandes categorias: os que compõem a estrutura da parede celular, que são de mais baixa disponibilidade no processo de digestão, e aqueles contidos no conteúdo celular, de maior disponibilidade.

Os componentes do conteúdo celular envolvem substâncias solúveis em água ou levemente solúveis em água: amido, lipídios e algumas proteínas que são digeridas tanto por enzimas de microorganismos, quanto por aquelas secretadas pelo aparelho digestivo dos animais. Os compo- nentes da estrutura da parede celular incluem, em sua maior parte, carboidratos e outras substâncias como a lignina, cuja digestão é totalmente dependente da atividade enzimática dos microorganismos do trato gastrointestinal dos ruminantes (Van Soest, 1994).

Estas diferenças nos resultados das análises químicas de forragens ocorridas com as mudanças morfológicas da planta resultam da interação estádio de desenvolvimento da planta $\times$ ambiente em que se desenvolve no ecossistema pastagem. Entre os fatores climáticos, a temperatura tem papel primordial sobre a qualidade da forragem. Temperaturas elevadas comprometem a digestibilidade da MS da forragem, seja de gramíneas ou leguminosas e de colmos ou folhas (Wilson, 1982; Wilson et al., 1991). A baixa digestibilidade observada em plantas que se desenvolvem sob condições de elevadas temperaturas pode ser atribuída a dois principais fatores: primeiro, as atividades metabólicas da planta aceleram sob altas temperaturas de crescimento, o que causa decréscimo no conjunto de metabólitos do conteúdo celular, e segundo, altas temperaturas ambientais resultam em aumento da lignificação da parede celular (Van Soest, 1994). Sob condições de campo, os fatores climáticos interagem determinando alterações qualitativas na planta forrageira.

Objetivou-se com esta pesquisa avaliar os efeitos da adubação nitrogenada, no período das águas, e do resíduo da adubação nitrogenada das águas, no período seco, em área com e sem controle do balanço hídrico sobre a composição químico-bromatológica da planta inteira e das lâminas foliares do capim-elefante sob pastejo.

\section{Material e Métodos}

As informações referentes ao local do experimento, ao tipo, às condições climáticas, ao manejo do pasto, aos tratamentos, ao delineamento experimental e às análises estatísticas constam em Mistura et al. (2006).

Em cada ciclo de pastejo, antes da entrada dos animais nos piquetes, foram amostradas três touceiras $\left(3 t_{c}\right)$ do capim-elefante, por tratamento, nas áreas irrigada e nãoirrigada. Cada touceira foi dividida ao meio, sendo metade colhida rente ao solo e a outra metade identificada para a colheita após o pastejo.

As plantas colhidas da metade de cada touceira foram separadas em perfilhos basais não-decapitados (PBNd com o meristema apical do perfilho principal) e decapitados ( $\mathrm{PBd}$ - sem o meristema apical do perfilho principal). Para cada categoria de perfilhos, retirou-se uma subamostra, que foi separada em material senescente (colmo + folhas mortas aderidas em partes vivas da planta, além das lâminas foliares 
com mais $50 \%$ senescida), lâminas foliares (parte da folha acima da lígula) e colmo (colmo + bainha das folhas).

Também, fez-se uma subamostra da planta inteira (colmo + folhas) acima de $0,80 \mathrm{~m}$ do solo, ou seja, descartou-se $0,80 \mathrm{~m}$ da parte inferior das plantas colhidas. As subamostras da planta inteira (PI) e das lâminas foliares das duas categorias de perfilho (LF-PBNd e LF-PBd) foram levadas para estufa de ventilação forçada a $65^{\circ} \mathrm{C}$ por 72 horas. Após secagem e pesagem, as amostras das lâminas foram trituradas em moinho, utilizando-se peneira com malha de $1 \mathrm{~mm}$,e analisadas quanto aos teores de PB, FDNe FDA com os valores corrigidos para $\mathrm{MS}$ a $105^{\circ} \mathrm{C}$.

Os teores de PB nas lâminas foliares das duas categorias de perfilho e da planta inteira foram determinadas pelo método Semimicro Kjeldahl e os teores de FDN e FDA, segundo Silva \& Queiroz (2002).

\section{Resultados e Discussão}

\section{Período das águas}

Os valores dos teores de PB nas lâminas foliares de capim-elefante ajustaram-se ao modelo linear crescente $(\mathrm{P}<0,05)$, em função das doses de $\mathrm{N}$, e variaram de 10,32 a $13,32 \%$ na planta inteira (PI) e de 12,40 a $16,06 \%$ e 11,66 a $15,23 \%$ nas lâminas foliares dos perfilhos basais não-decapitados (LF-PBNd) e decapitados (LF-PBd) na ANI, respectivamente (Figura 1). Estes resultados indicam que o capimelefante sob lotação intermitente com adubação nitrogenada proporcionou uma dieta com teores de $\mathrm{PB}$ que não limitaria $\mathrm{m}$ a atividade microbiana no rúmen (NRC, 2001). A elevação dos teores de PB em lâminas de capim-elefante com adubação nitrogenada também foi constatada por Ribeiro et al. (1999), Mistura (2001) e Lopes et al. (2005).

Ao se compararem os teores de $\mathrm{PB}$ nas lâminas foliares (LF-PBNd e LF-PBd) e na PI, observou-se que, além do aumento proporcionado pelo $\mathrm{N}$, as lâminas foliares também apresentam maiores valores. Por outro lado, o menor teor de PB na fração da PI é atribuído ao colmo (colmo + folha) como componente da MS analisada, que apresenta menor teor de PB, como demonstrado por Pedreira \& Boin (1969), Ribeiro et. al. (1999), Ezequiel \& Favoretto (2000), Gerdes et. al. (2000) e Mistura (2001).

Nota-se ainda (Figura 1) que as lâminas foliares provenientes das duas categorias de perfilho tiveram praticamente a mesma eficiência de resposta ao $\mathrm{N}$ aplicado, ou seja, para cada $\mathrm{kg}$ de $\mathrm{N}$ elevou-se $0,0122 \mathrm{~kg}$ de MS de lâminas foliares, valor inferior aos relatados por Ribeiro et. al. (1999) e Paciulllo (1997), que verificaram aumentos de 0,0430 e 0,0302 , respectivamente.

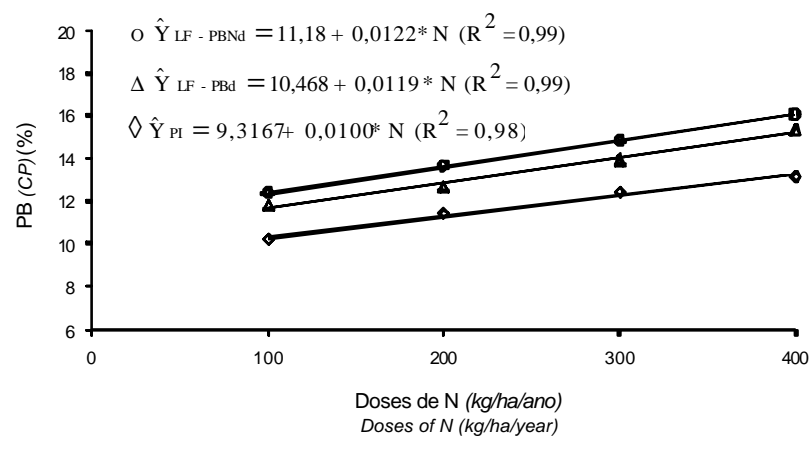

* Significativo pelo teste $t(P<0,05)$ (Significant by $t$ test).

Figura 1 - Estimativas dos teores de PB na planta inteira (PI) e nas lâminas foliares dos perfilhos basais não-decapitados (LF-PBNd) e decapitados (LF-PBd) do capimelefante, em função das doses de nitrogênio $(\mathrm{N})$, no período das águas.

Figure 1 - Estimates of $C P$ concentration in the whole plant (PI) and in the leaf blade of non-decapitated basal tiller ( $L F-P B N d)$ and leaf blade of decapitated basal tiller (LF-PBd) of elephantgrass according to the $\mathrm{N}$ levels, in the rainy season.

Constatou-se também superioridade nos valores de PB nas LF-PBNd, que pode ser atribuída ao efeito de diluição dos PBd, por conter maior produção de MS por unidade de perfilho, em razão do maior perfilhamento aéreo. Resultados semelhantes foram constatados por Lambertucci et al. (2003), ao analisarem os teores de PB do limbo foliar (asa), da quilha (nervura central) e lâmina foliar (quilha + limbo foliar), para as duas categorias de perfilho.

O teores de FDN da fração LF-PBd do capim-elefante no período das águas aumentaram linearmente $(\mathrm{P}<0,05)$ em função das doses de N, com valores entre 75,39 e 77,49 para as doses de 100 e $400 \mathrm{~kg} / \mathrm{ha}$, respectivamente. Entretanto, na PI e LF-PBd, não foi detectado efeito da adubação nitrogenada sobre os teores de FDN, observando-se valores médios de 77,03 e 75,36\%, respectivamente (Figura 2). Os valores observados na PI e nos dois tipos de perfilhos foram semelhantes, comprovando o pequeno efeito do $\mathrm{N}$ sobre os teores de FDN.

No entanto, os altos valores de FDN nos PBNd do capim-elefante adubado com $\mathrm{N}$ podem ser atribuídos aos fatores climáticos favoráveis e à maior disponibilidade de nutrientes minerais na solução do solo, que proporcionaram maior crescimento e desenvolvimento dos perfilhos tanto dos PBNd (11,64 a 18,65 g/perfilho) como dos PBd (22,46 a $33,05 \mathrm{~g} /$ perfilho), respectivamente, nas doses de 100 e 400 $\mathrm{kg} /$ ha de N (Figura 2). Nestes perfilhos com maiores acúmulos de MS (g/perfilho), também ocorreram maiores proporções de tecidos de sustentação nas frações colmo e quilha em relação às lâminas foliares e no limbo foliar (lâmina foliar sem 


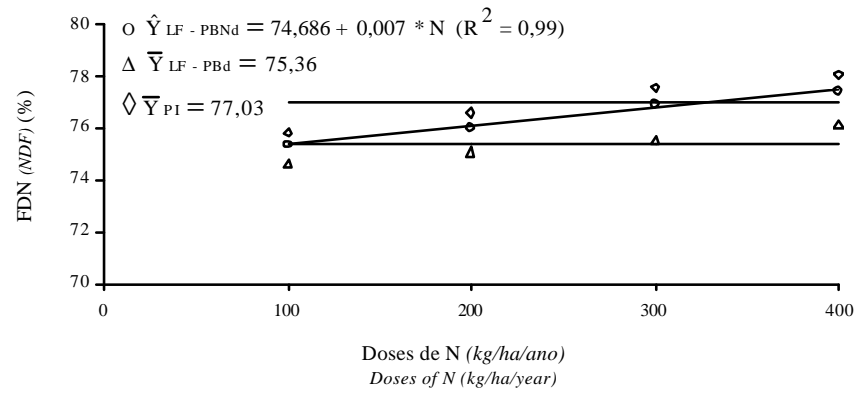

* Significativo pelo teste $t(P<0,05)$ (Significant by $t$ test).

Figura 2 - Estimativas dos teores de FDN na planta inteira (PI) e nas lâminas foliares dos perfilhos basais não-decapitados (LF-PBNd) e decapitados (LF-PBd) do capimelefante, em função das doses de N, no período das águas.

Figure 2 - Estimates of NDF concentration in the whole plant (WP) and in the leaf blade of non-decapitated basal tiller (SF-NDBT) and leaf blade of decapitated basal tiller (SF-DBT) of elephantgrass according to the $N$ doses, in the rainy season.

nervura central). Essa maior proporção de colmo e quilha, que são as frações da planta com maiores proporções de tecidos estruturais (esclerênquima e xilema), com parede celular espessa e lignificada, contribui para elevação dos teores de FDN (Alkin, 1989; Wilson, 1993). Neste contexto, Alves de Brito et al. (1999), ao quantificarem a porcentagem dos diferentes tecidos estruturais presentes na folha e no colmo, constataram maiores proporções de tecidos vasculares lignificados com esclerênquimas e parenquimáticos na quilha e no colmo em relação ao limbo e bainha foliar, que possuem maiores proporções de tecidos da epiderme e mais digestíveis.

Assim, com a aplicação do $\mathrm{N}$ em uma pastagem, tem-se maior taxa de crescimento de perfilhos de gramíneas, que na fase inicial de desenvolvimento são constituídas basicamente por folhas e pseudocolmo. Com a maturidade dos perfilhos, outras frações do colmo passam a contribuir para o acúmulo de seus pesos, diminuindo a relação folha/colmo (Dervin Dean et al., 1992; Acunha \& Coelho, 1997; Kozloski et al., 2003). Esse incremento na fração colmo, com o avanço da idade da planta, reduz a digestibilidade (Alves de Brito et al., 1999; Ribeiro et al., 1999; Mistura, 2001), em conseqüência da elevação dos teores de FDN na planta.

Por outro lado, os incrementos nos teores de FDN nas lâminas foliares das duas categorias de perfilho (LF-PBNd e LF-PBd), com as doses adubação nitrogenada (Figura 2), também podem estar associados à maior proporção de tecidos de sustentação - neste caso composto pela quilha (nervura central da folha) - principalmente na LF-PBNd, que possui maiores tamanhos de folhas em relação ao
LF-PBd (Casagrande et al., 2003), em resposta à adubação nitrogenada (Santos et al., 2004). Esses autores encontraram relação limbo/quilha de 2,31 e 2,85, respectivamente, para lâminas foliares de PBNd e PBd. A quilha, por possuir maiores proporções de tecidos com menores digestibilidades (tecido vascular lignificado com esclerênquima e tecidos parenquimáticos) em relação ao restante da lâmina foliar (limbo) (Alves de Brito et al., 1999), proporciona maiores teores de FDN.

Estes incrementos nos teores de FDN com a adubação nitrogenada corroboram os resultados obtidos por Ribeiro et al. (1999) e Mistura (2001), em lâminas foliares de capimelefante adubado com nitrogênio. Outros autores, entretanto, não detectaram diferenças acentuadas nos teores de FDN em resposta à adubação nitrogenada (Moir, 1974; Ribeiro et al., 1999).

Os teores de FDA nas lâminas foliares de PBNd e PI de capim-elefante adubado com $\mathrm{N}$ aumentaram de forma linear crescente $(\mathrm{P}<0,05)$, ao passo que, nas lâminas dos $\mathrm{PBd}$, não foi detectado efeito do N sobre os teores de FDA (Figura 3). Os incrementos nos teores de FDA proporcionais às doses de $\mathrm{N}$ nas PBNd decorreram das alterações nos componentes estruturais da planta resultantes da variação de estádios de maturidade acelerada pela adubação e pelos fatores climáticos favoráveis, conforme discutido anteriormente para FDN. No caso da FDA, que é constituída de celulose e lignina, que estão relacionadas com a sustentação da planta (colmo e quilha) (Alves De Brito \& Dechamps, 2001), ocorre aumento de seus teores com o avanço da idade da planta (Paciullo et al., 2001).

Os maiores teores de FDA na PI em relação às lâminas foliares de ambas as categorias de perfilhos (Figura 3) podem ser atribuídos à partição do colmo em constituintes com maiores frações de tecidos lignificados que a fração lâminas foliares. Esta mesma tendência dos teores de FDA, à semelhança da FDN, indica que houve também maturidade da planta em decorrência da maior taxa de crescimento proporcionado pelo $\mathrm{N}$ (desenvolvimento do colmo), que elevou os teores de FDA (Ribeiro et al., 1999; Mistura, 2001). Neste contexto, Da Silva (1993), Santos (1993) e Nussio et al. (1998) afirmam que a taxa de digestibilidade reduz com a elevação das doses de $\mathrm{N}$, uma vez que a taxa de crescimento da planta é drasticamente incrementada.

Além do $\mathrm{N}$ que contribui para alterar a fenologia da planta, os fatores climáticos também influem nos teores de FDA e FDN. Segundo Van Soest (1994), a baixa digestibilidade observada em plantas desenvolvidas sob condições de elevadas temperaturas apresenta maior lignificação da parece celular e atividades metabólicas, oque causa decréscimo no "pool" de metabólitos do conteúdo celular. Assim, os 


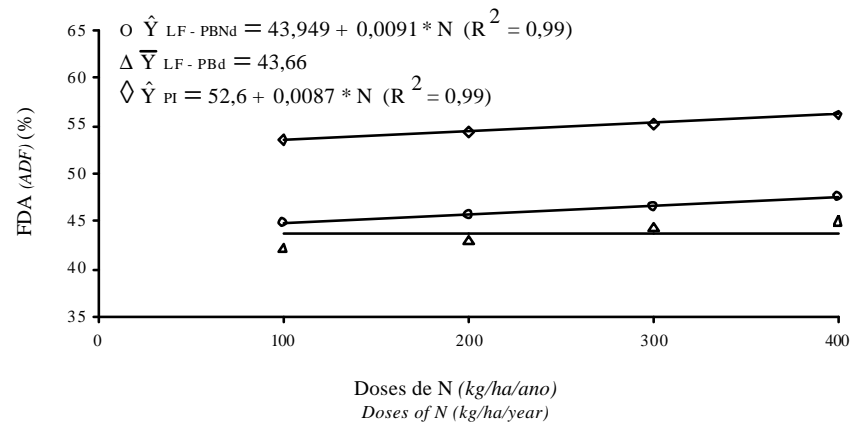

* Significativo pelo teste $t(P<0,05)$ (Significant by $t$ test).

Figura 3 - Estimativas dos teores de FDA na planta inteira (PI) e nas lâminas foliares dos perfilhos basais não-decapitados (LF-PBNd) e decapitados (LF-PBd) do capimelefante, em função das doses de $\mathrm{N}$, no período das águas.

Figure 3 - Estimates of ADF concentration in the whole plant (WP) and in the leaf blade of non-decapitated basal tiller (SF-NDBT) and leaf blade of decapitated basal tiller (SF-DBT) according to the $N$ doses, in the rainy season.

produtos fotossintéticos são mais rapidamente convertidos em componentes estruturais.

\section{Período seco}

Os teores de PB nas lâminas foliares (LF-PBNd e LF-PBd) do capim-elefante no período seco sem irrigação (ANI), em função do resíduo de $\mathrm{N}$ no período das águas, ajustaram-se a modelos lineares crescentes $(\mathrm{P}<0,05)$, ao passo que, na área irrigada (AI), os teores de $\mathrm{PB}$ na $\mathrm{PI}$ reduziram $(\mathrm{P}<0,05)$ e na $\mathrm{LF}-\mathrm{PBNd}$ aumentaram linearmente $(\mathrm{P}<0,05)$, em função dos resíduos de $\mathrm{N}$ das águas acrescidos do restante do parcelamento das doses de N (Figura 4). Observa-se que os teores de PB nas três partes da planta apresentaram valores semelhantes, o que leva a concluir que o teor de PB formado no período das águas se manteve no período seco, independentemente da irrigação. Isto sugere que um bom manejo no período das águas é essencial para se obterem teores de PB suficientes no período seco.

Os incrementos nos valores protéicos nas lâminas foliares de ambas as categorias de perfilhos na ANI indicam o efeito residual da adubação do período anterior (águas) sobre a qualidade da forragem no período seco (Figura 4), porém inferiores ao do período das águas (Figura 1). Por outro lado, a ausência de efeito sobre os teores de PB na PI deve-se ao efeito de diluição resultante da partição do colmo.

Os maiores teores de $\mathrm{PB}$ no período das águas em relação ao período seco podem ser atribuídos, primeiramente, às condições climáticas favoráveis (Mistura et al., 2006; Figuras 1 e 2), que permitiram maior eficiência na
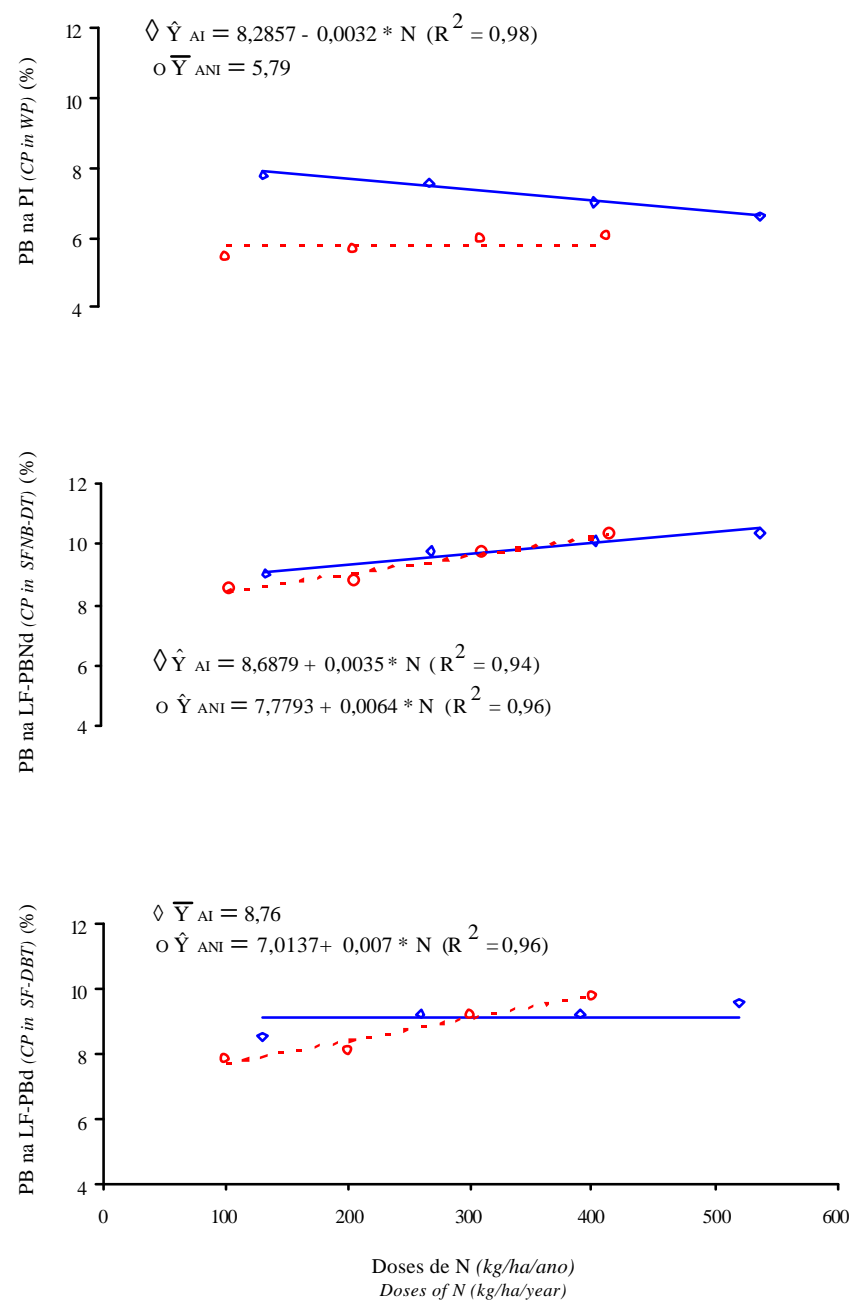

* Significativo pelo teste $t(P<0,05)$ (Significant by $t$ test).

Figura 4 - Estimativas dos teores de PB na planta inteira (PI) e nas lâminas foliares dos perfilhos basais não-decapitados (LF-PBNd) e decapitados (LF-PBd) do capimelefante, em função das doses de $\mathrm{N}$, em áreas irrigada (Al) e não-irrigada (ANI), no período seco.

Figure 4 - Estimates of $C P$ concentration in the whole plant (WP) and in the leaf blade of non-decapitated basal tiller (SF-NDBT) and leaf blade of decapitated basal tiller (SF-DBT) of elephantgrass according to the $N$ doses, in the irrigated (Al) and non-irrigated area (ANI), in the dry season.

absorção do $\mathrm{N}$ e, conseqüentemente, maiores concentrações de PB na planta (Gerdes et al., 2000; Balsalobre et al., 2003; Santos et al., 2001).

A redução nos teores de $\mathrm{PB}$ da PI, no período seco na $\mathrm{AI}$, com as doses de $\mathrm{N}$ aplicadas no período das águas, pode ser explicada pelo maior crescimento das plantas, o qual resultou em maiores acúmulos de colmos nos resíduos de plantas acima da altura do pasto pós-pastejo $(0,80 \mathrm{~m}$ acima do nível do solo). Este excesso de colmo influenciou a composição da amostra no período seco, resultando em resposta negativa (Figura 4). 
Por outro lado, os teores de PB nas lâminas foliares das duas categorias de perfilhos apresentaram valores semelhantes entre a AI e ANI, apesar de a AI ter recebido $30 \%$ da dose de $\mathrm{N}$ do período das águas, no período seco (Figura4). Esta semelhança nos teores de PB pode estar associada ao efeito de diluição na MS da AI, resultante da maior produção em relação à da ANI.

A irrigação no período seco do ano proporcionou maiores teores de PB apenas na PI, por permitir maior crescimento e, ou, desenvolvimento das plantas, resultando em maiores proporções de lâminas foliares, quando comparada à ANI.

Por outro lado, ao considerar apenas as lâminas foliares doPBNd e PBd, sem a inclusão do colmo (Figura 4), observou-se que, além de maiores teores de $\mathrm{PB}$, não foi detectado efeito da irrigação, o que também foi observado por Botrel et al. (1992), Lopes et al. (2005) e Mistura (2001).

O teores de FDN na PI, LF-PBNd e LF-PBd do capimelefante não foram influenciados pelos resíduos do adubo nitrogenado do período das águas, tanto na ANI como na AI (Figura 5).

A ausência de efeito da adubação nitrogenada sobre os teores de FDN na parte aérea do capim-elefante na AI e ANI, no período seco, pode estar associada às pequenas variações ocorridas na estrutura da lâmina foliar, em decorrência da menor disponibilidade dos fatores abióticos, que resultou em menor acúmulo de forragem. Esta redução no acúmulo da MS, no período seco, decorre de alterações nas características estruturais dos perfilhos (Lambertucci et al., 2004) - como o tamanho de folhas -, que provavelmente também reduziram as proporções dos tecidos estruturais das lâminas foliares (quilha). Além disso, também na PI, ocorreu menor diferenciação na proporção de colmo, em decorrência das menores taxas de crescimento no período seco, o que pode ter contribuído para menores variações entre os teores de fibra nas diferentes frações da planta, em função dos resíduos das doses de N na AI e ANI.

Observa-se ainda que a irrigação e o parcelamento das doses de N não influíram no percentual de FDN, nas três partes da planta estudadas (Figura 5). Isto sugere que, no período seco, a adubação residual do período das águas, não reduz a qualidade da forragem, quanto a este nutriente.

Variações nos teores de FDN entre os períodos do ano também foram verificadas por Paciullo et al. (2001) e Balsalobre et al. (2003), que relataram maiores teores de FDN (tanto no colmo como nas lâminas foliares) no período das águas. Os mais altos valores dos constituintes da parede celular no verão reforçam os efeitos, principalmente, das elevadas temperaturas nesta estação sobre a composição da forragem.
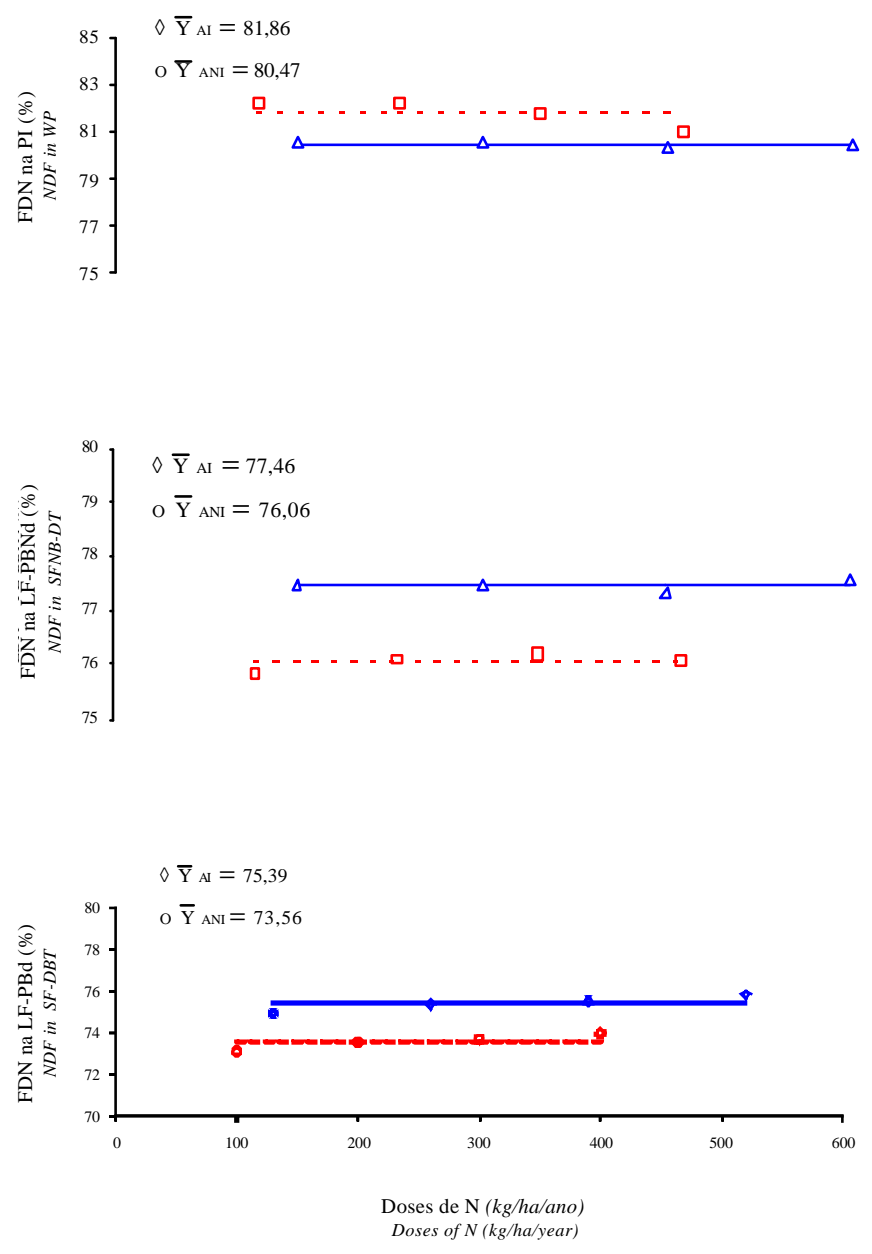

Significativo pelo teste $t(P<0,05)$ (Significant by $t$ test).

Figura 5 - Estimativas dos teores de FDN na planta inteira (PI) e nas lâminas foliares dos perfilhos basais não-decapitados (LF-PBNd) e decapitados (LF-PBd) do capimelefante, em função das doses de $\mathrm{N}$, em áreas irrigada (AI) e não-irrigada ( $\mathrm{ANI}$ ), no período seco.

Figure 5 - Estimates of NDF concentration in the whole plant (WP) and in the leat blade of non-decapitated basal tiller (SF-NDBT) and leaf blade of decapitated basal tiller (SF-DBT) according to the $N$ doses, in irrigated area (Al) and non-irrigated area (ANI), in the dry season.

Por outro lado, a irrigação no período seco do ano proporcionou vantagens relativas nos teores FDN na PI, na $\mathrm{AI}$, em todas as doses de $\mathrm{N}$, por permitir maior acúmulo de lâminas foliares, que diluiu o efeito da fração do colmo (fração da planta mais lignificada). Nas lâminas foliares (PBNd e PBd), na AI, houve desvantagem em todas as doses de $\mathrm{N}$, em razão do maior desenvolvimento da planta com lâminas foliares de maiores tamanhos, necessitando de maiores proporções de tecidos de sustentação (quilha), que incrementam os teores de FDN (Figura 5). Com isso, na ANI, com crescimento limitado, observaram-se menores teores FDN nas lâminas foliares e maiores na PI. 
Os teores de FDA na parte aérea do capim-elefante, no período seco, apresentaram resposta linear positiva $(\mathrm{P}<0,05)$ apenas para PI, na AI, em função dos resíduos das doses de $\mathrm{N}$ acrescido do restante do adubo aplicado no período das águas. Na ANI, porém, não houve efeito sobre nenhuma fração da planta em resposta aos resíduos da adubação nitrogenada (Figura 6).
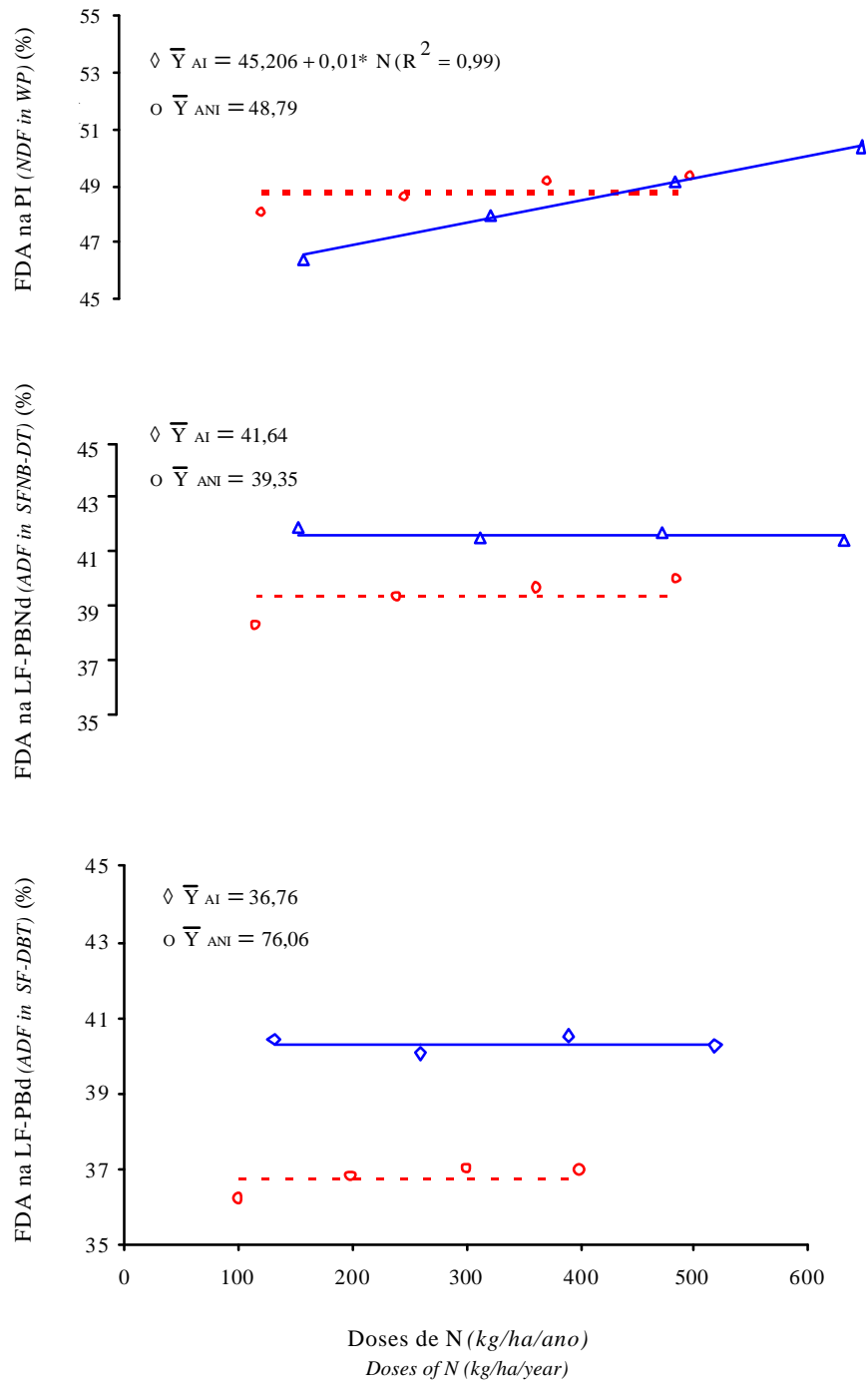

Significativo pelo teste $t(P<0,05)$ (Significant by $t$ test).

Figura 6 - Estimativas dos teores de FDA na planta inteira $(\mathrm{PI}) \mathrm{e}$ nas lâminas foliares dos perfilhos basais não-decapitados (LF-PBNd) e decapitados (LF-PBd) do capimelefante, em função das doses de nitrogênio $(\mathrm{N})$, em áreas irrigada ( $\mathrm{Al}$ ) e não-irrigada ( $\mathrm{ANI})$, no período seco.

Figure 6 - Estimates of ADF concentration in the whole plant (WP) and in the leaf blade of non-decapitated basal tiller (SF-NDBT) and leaf blade of decapitated basal tiller (SF-DBT) of elephantgrass according to the $N$ doses, in irrigated area (Al) and non-irrigated area $(A N I)$, in the dry season.
As baixas variações nos teores de FDA com a adubação $\mathrm{N}$ no capim-elefante, no período seco, tanto na AI como na ANI, podem ser explicadas pelas mesmas justificativas apresentas nas discussões dos teores de FDN nas diferentes respostas analisadas.

O efeito linear positivo da adubação nitrogenada sobre os teores de FDA na PI na AI, no período seco, deve-se aos maiores acúmulos de resíduos de pasto (praticamente composto por colmo) acima da altura pré-determinada na pastagem $(0,80 \mathrm{~m}$ acima do nível do solo). Este excesso do colmo, ao permanecer sobre os perfilhos vivos, influenciou a composição das amostras de MS colhidas no período seco, resultando em maiores incrementos nos teores de fibra (Figura 6). Observa-se que os teores de FDA na PI da AI foram menores que os da ANI, para as doses mais baixas de $\mathrm{N}$.

Ainda de acordo com a Figura 6, percebe-se que, para os teores de FDA, é menos vantajoso irrigar (AI) na presença de $30 \%$ da adubação de $\mathrm{N}$ em relação à ANI. Este acréscimo em FDA na AI pode ser atribuído ao maior desenvolvimento da planta, que aumentou o metabolismo, com incremento da parede celular (Van Soest, 1994), resultado também obtido por Lopes et al. (2005).

\section{Conclusões}

A composição químico-bromotológica de todas as partes aéreas das plantas de capim-elefante, no período das águas, foi incrementada com a adubação nitrogenada.

O resíduo da adubação nitrogenada do período das águas aumentou os teores protéicos das lâminas foliares do capim-elefante, no período seco, com e sem controle do balanço hídrico, enquanto as concentrações na planta inteira reduziram com irrigação.

O controle do balanço hídrico pela irrigação promoveu maiores incrementos de fibra na forragem nas frações lâminas foliares nos perfilhos basais não-decapitados e decapitados do capim-elefante, e menores na planta inteira.

\section{Literatura Citada}

ACUNHA, J.B.V.; COELHO, R.W. Efeito da altura e intervalo de corte do capim-elefante anão. I - Produção e qualidade da forragem. Pesquisa Agropecuária Brasileira, v.32, n.1, p.117-132, 1997.

ALKIN, DE. Histological and physical factors affecting digestibility of forages. Agronomy of Journal, v.81, n.1, p.17-25, 1989.

ALVES DE BRITO, C.J.F.; DESCHAMPS, F.C. Caracterização anatômica em diferentes frações de cultivares de capim-elefante (Pennisetum purpureum Schumach.). Revista Brasileira de Zootecnia, v.30, n.5, p1409-1417, 2001.

ALVES DE BRITO, C.J.F.; RODELLA, R.A.; DESCHAMPS, F.C. et al. Anatomia quantitativa e degradação in vitro de tecidos em 
cultivares de capim-elefante (Pennisetum purpureum Schumach.). Revista Brasileira de Zootecnia, v.28, n.2, p.223-229, 1999.

BALSALOBRE, M.A.A.; CORSI, M.; SANTOS, P.M. et al. Composição química e fracionamento do nitrogênio e dos carboidratos do capim-tanzânia irrigado sob três níveis de resíduo pós-pastejo. Revista Brasileira de Zootecnia, v.32, n.3, p.519-528, 2003.

BOTREL, M.A.; ALVIM, M.J.; XAVIER, D.F. Efeitos da irrigação sobre algumas características agronômicas de cultivares de capim-elefante. Pesquisa Agropecuária Brasileira, v.26, p.1731-1736, 1992.

CASAGRANDE, D.R.; MISTURA, C.; FONSECA, D.M. et al Características estruturais de perfilhos em pastagem de capimelefante adubado com nitrogênio. In: REUNIÃO ANUAL DA SOCIEDADE BRASILEIRA DE ZOOTECNIA, 40., 2003, Santa Maria. Anais... Santa Maria: Sociedade Brasileira de Zootecnia, 2003. (CD-ROM).

CORSI, M.; SILVA, S.C.; FARIA, V.P. Princípios de manejo do capim-elefante sob pastejo. Informe Agropecuário, v.19, n.192, p.36-43, 1998

Da SILVA, S.C. Manejo de plantas forrageiras dos gêneros Brachiaria, Cynodon e Setária. In: PEIXOTO, A.M.; MOURA, J.C.; FARIA, V.P. (Eds.) Volumosos para bovinos. 2.ed. Piracicaba: Fundação de Estudos Agrários Luiz de Queiroz, 1993. p.29-58

DERVIN DEAN, G.; TYRONE CLAVERO, C.; MAX VENTURA, S. Evaluación cualitativa de cuatro henos de pasto elefante enano (Pennisetum purpureum cv Mott). Revista Faculdade Agronomia, v.9, p.115-124, 1992.

EZEQUIEL, J.M.B.; FAVORETTO, F. Efeito do manejo sobre a produção e composição química de perfilhos do capim-colonião (Panicum maximum Jacq.). Revista Brasileira de Zootecnia v.29, n.6, p.1596-1607, 2000

FERREIRA, J.J. Alternativas de suplementação e valor nutritivo do capim-elefante sob pastejo rotacionado. Informe Agropecuário, v.19, n.192, p.66-72, 1998

GERDES, L.; WENER, J.C.; COLOSSA, M.T. et al. Avaliação das características de valor nutritivo das gramíneas forrageiras Marandu, Setária, Tanzânia nas estações do ano. Revista Brasileira de Zootecnia, v.29, n.4, p.955-963, 2000.

KOZLOSKI, G.V.; PEROTTONI, J.; CIOCCA, M.L.S. et al. Potential nutritional assessment of dwarf elephant grass (Pennisetum purpureum Schum. cv. Mott) by chemical composition, digestion and net portal flux of oxygen in cattle. Animal Feed Science And Tecnology, v.105, n.1-4, p.29-40, 2003.

LAMBERTUCCI, D.M.; MISTURA, C.; FONSECA, D.M. et al. Características estruturais doPennisetum purpureum cv. Napier adubado com nitrogênio.In: REUNIÃO ANUAL DA SOCIEDADE BRASILEIRA DE ZOOTECNIA, 41., 2004, Campo Grande. Anais... Campo Grande: Sociedade Brasileira de Zootecnia, 2004. (CD-ROM).

LAMBERTUCCI, D.M.; MISTURA, C.; FONSECA, D.M. et al. Qualidade de diferentes frações da lâmina foliar em pastagem de capim-elefante adubada com nitrogênio. In: REUNIÃO ANUAL DA SOCIEDADE BRASILEIRA DE ZOOTECNIA, 40., 2003, Santa Maria. Anais... Santa Maria: Sociedade Brasileira de Zootecnia, 2003. (CD-ROM).

LOPES, R.S. Efeito da irrigação e adubação na disponibilidade e composição bromatológica da massa seca de lâminas foliares de capim-elefante. Revista Brasileira de Zootecnia, v.34, n.1, p.20-29, 2005.

MISTURA, C. Doses crescente de nitrogênio e fósforo na produção e qualidade do capim-elefante-anão (Pennisetum purpureum Schum.) cv. Mott. Pelotas: Universidade Federal de Pelotas, 2001. 88p. Dissertação (Mestrado em Ciências) Universidade Federal de Pelotas, 2001

MISTURA, C.; FONSECA, D.M.; FAGUNDES, J.L. et al. Efeito da adubação nitrogenada e irrigação sobre a disponibilidade de matéria seca, número e peso de perfilhos em pastagem de capim- elefante. Revista Brasileira de Zootecnia, v.35, n.2, p.372379, 2006

MOIR, K.W. The constancy of the digested cell wall in grasses. Journal of Agricultural Science, v.83, n.2, p.259-258, 1974

NATIONAL RESEARCHCOUNCIL - NRC. Nutrient requirements of dairy cattle. 7.ed. Washington, D.C.: Academic Press, 2001. $381 \mathrm{p}$.

NUSSIO, L.G.; MANZANO, R.P.; PEDREIRA, C.G.S. Valor alimentício em plantas do gênero Cynodon. In: SIMPÓSIO SOBRE MANEJO DA PASTAGEM: MANEJO DE PASTAGENS DE TÍFTON, COASTCROSS E ESTRELA, 15., 1998, Piracicaba. Anais... Piracicaba: Fundação de Estudos Agrários Luiz de Queiroz, 1998. p.203-242.

PACIULLO, D.S.C; GOMIDE, J.A.; QUEIROZ, D.S. et al. Composição química e digestibilidade in vitro de lâminas foliares e colmos de gramíneas forrageiras, em função do nível de inserção no perfilho, da idade da planta e da estação de crescimento. Revista Brasileira de Zootecnia, v.30, n.3, p.964-974, 2001 (supl. 1).

PEDREIRA, J.V.S.; BOIN, C. Estudo de crescimento do capimelefante variedade Napier (Pennisetum purpureum Schum.), Boletim da Indústria Animal, n.26, p.263-273, 1969.

QUEIROZ, D.S.; GOMIDE, J.A.; MARIA, J. Avaliação da folha e colmo de topo e base de perfilho de três gramíneas forrageiras. 1. Digestibilidade in vitro e composição química. Revista Brasileira de Zootecnia, v.29, n.1, p.53-60, 2000.

REIS, R.A.; RODRIGUES, L.R.A. Valor nutritivo de plantas forrageiras. Jaboticabal: Universidade Estadual Paulista, 1993. $26 \mathrm{p}$.

RIBEIRO, K.G.; GOMIDE, J.A.; PACIULLO, D.S.C. Adubação nitrogenada do capim-elefante cv. Mott. 2. Valor nutritivo ao atingir 80 e $120 \mathrm{~cm}$ de altura. Revista Brasileira de Zootecnia, v.28, n.6, p.1194-1202, 1999.

SANTOS, E.A.; SILVA, D.S.; QUEIROZ FILHO, J.L. Composição química do capim-elefante cv. Roxo cortado em diferentes alturas. Revista Brasileira de Zootecnia, n.30, n.1, p.1823, 2001 .

SANTOS, F.A.P. Manejo de pastagens de capim colonião. In: PEIXOTO, A.M.; MOURA, J.C.; FARIA, V.P. (Eds.) Volumosos para bovinos. Piracicaba: Fundação de Estudos Agrários Luiz de Queiroz, 1993. p.21-28.

SANTOS, M.R.; MISTURA, C.; FONSECA, D.M. et al. Efeito da adubação nitrogenada sobre os constituintes da lâmina foliar do capim-elefante irrigado. In: REUNIÃO ANUAL DA SOCIEDADE BRASILEIRA DE ZOOTECNIA, 41., 2004, Campo Grande. Anais... Campo Grande: Sociedade Brasileira de Zootecnia, 2004. (CD-ROM).

SILVA, D.J.; QUEIROZ, A.C. Análise de alimentos: métodos químicos e biológicos. 3.ed. Viçosa, MG: Editora UFV, 2002. $235 \mathrm{p}$.

Van SOEST, P.J. Nutritional ecology of the ruminant. 2.ed. Ithaca: Cornell University, 1994. 476p.

WILSON, J.R. Organization of forage plant tissues. In: JUNG, H.G.; BUXTON, D.R.; HATFIELD, R.D. (Eds.) et al. Forage cell wall structure and digestibility. Madison: American Society of Agronomy, Crop Science Society of America, Soil Science of America, 1993. p.1-32.

WILSON, J.R. Environmental and nutritional factors affecting herbage quality. In: HACKER, J.B. (Ed.). Nutritional limits to animal production from pastures. Sta Lucia: Commonwealth Agricultural Bureaux, 1982. p.111-113.

WILSON, J.R.; DEINUM, B.; ENGELS, F.M. Temperature effects on anatomy and digestibility of leaf and stem of tropical and temperate forage species. Netherlands Journal Agricultural Science, v.30, n.1, p.31-48, 1991 